\title{
In vitro versus In vivo: Development-, Apoptosis-, and Implantation- Related Gene Expression in Mouse Blastocyst
}

\author{
Forough Mahdavinezhad ${ }^{1}$, Parinaz Kazemi ${ }^{1,2}$, ParisaFathalizadeh ${ }^{1}$, Fatemeh Sarmadi ${ }^{1}$, Leila Sotoodeh ${ }^{1}$, \\ Ehsan Hashemi ${ }^{1}$, Hadi Hajarian ${ }^{3}$, Mojtaba Dashtizad 1,* \\ ${ }^{1}$ Embryo Biotechnology Laboratory (Embio Lab), Department of Animal Biotechnology, National Institute of Genetic \\ Engineering and Biotechnology (NIGEB), Tehran, Iran \\ ${ }^{2}$ McGill University Research Institute of the McGill University Health Centre, Montreal, Quebec, Canada \\ ${ }^{3}$ Department of Animal Science, Razi University, Kermanshah, Iran \\ * Corresponding author: Mojtaba Dashtizad, Department of Animal Biotechnology, National Institute of Genetic Engineering and Biotechnology, Tehran, \\ Iran. Tel: +98-21-44787323; Fax: +98-21-44780395; E-mail: dashtizad@nigeb.ac.ir
}

Background: While mammalian embryos can adapt to their environments, their sensitivity overshadows their adaptability in suboptimal in vitro conditions. Therefore, the environment in which the gametes are fertilized or to which the embryo is exposed can greatly affect the quality of the embryo and consequently its implantation potential. Objectives: Since providing an optimal culture condition needs a deep understanding of the environmental effects, and regarding the fact that normal morphology fails to be a reliable indicator of natural embryo development, the current study aimed at comparing in vivo- and in vitro-derived blastocysts at the molecular level.

Materials and Methods: In vivo and in vitro mouse blastocysts were obtained by flushing the uterine horns and in vitro fertilization/culture, respectively. Normal blastocysts of both groups were evaluated in terms of hatching rate and expression of three lineage-differentiation-, apoptosis-, and implantation-related genes.

Results: The hatching rate was lower in In vitro fertilization (IVF)-produced blastocysts in comparison with that of the in vivo counterparts. More importantly, the study results indicated significant changes in the expression levels of eight out of ten selected genes, especially Mmp-9 (about -10.7-fold). The expression of Mmp-9 in trophoblast cells is required for successful implantation and trophoblast invasion.

Conclusions: The current study, in addition to confirming that the altered gene expression pattern of in vitro-produced embryos resulted in normal morphology, provided a possible reason for lower implantation rate of in vitro-produced blastocysts regarding the $\mathrm{Mmp}-9$ expression.

Keywords: Gene Expression; Fertilization in vitro; Matrix Metalloproteinase 9

\section{Background}

In vitro culture (IVC) of preimplantation embryo is undoubtedly an essential step in assisted reproductive technologies such as in vitro fertilization (IVF) and intracytoplasmic sperm injection, as well as embryonic stem cell studies $(1,2)$. Mammalian preimplantation embryo development period extends from fertilization of mature oocyte to implantation of the late blastocyst (3). During this interval, many important events including maternal to zygotic genome transition, compaction, first three lineage differentiation, and blastocyst formation occur. These events seem to be affected by gamete quality and culture conditions (4) such as culture media components, $\mathrm{pH}$, osmolarity, temperature, oxygen tension, and humidity of incubator (5-7).
Despite the significant improvements in the quality of culture media $(8,9)$, it seems that none of the available ones can fully mimic the physiological conditions of the female tract (10). In this regard, many studies in different species show that environmental stresses can cause serious changes in morphology and cell metabolism (11-17), affecting the quality of the embryo and consequently its implantation potential $(18,19)$. In vitro-produced embryos have comparably higher lipid accumulation in the cytoplasm (20), more fragile zona pellucida (21), higher chromosomal abnormality (22), smaller nucleoplasmic rate (23), and reduced total number of cells (24). The origin of these cellular and sub-cellular differences between in vivo- and in vitroderived embryos can be traced to gene expression alterations (25). In fact, although embryos can adapt to 
an artificial environment, suboptimal conditions might immediately affect gene expression. However, the consequences might not be evident until later stages of embryo development, fetus phase or even postnatal period $(26,27)$.The first sign of these invisible effects is low rate of implantation even after transferring a morphologically normal embryo $(18,28,29)$. Since the normal morphology of an embryo fails to guarantee its high quality, in vitro culture conditions are favored to be further assessed at molecular levels. In fact, identifying genes with different expression patterns in in vitro environment may facilitate providing an optimal culture condition with more appropriate factors.

\section{Objectives}

The current study aimed at comparing the hatching rate and the expression of selected genes related to developmental potential, implantation ability, and apoptosis between in vivo- and in vitro-derived mouse blastocysts. More specifically, the study examined relative levels of caudal-type homeobox $2(\mathrm{Cd} 2)$ and eomesodermin (Eomes), both involved in trophectoderm differentiation (30); pluripotencysustaining factors POU class 5 homeobox 1 transcription factor (Pou5f1, formerly Oct4) and Nanog homeobox protein (Nanog), essential for inner cell mass formation (31); GATA-binding factor 6 (Gata6), the growth receptor bound protein 2 (Grb2)-RAS-mitogenactivated protein (MAP) kinase signaling (32), drives differentiation towards the primitive endoderm; and matrix metalloproteinase 9 (Mmp-9), associated with extracellular matrix degradation during implantation process (33). Furthermore, transformation-related protein 53 (Trp53), which plays a critical role in the initiation of apoptosis and its downstream target genes, Bcl2-associated X (Bax), and B-cell lymphoma 2 $(B c l 2)$, were chosen as proxies to understand how in vitro culture stresses the embryo $(34,35)$.

\section{Materials and Methods}

All mice were housed in the National Institute of Genetic Engineering and Biotechnology (NIGEB), Tehran, Iran. Facility and procedures of using these mice were reviewed and approved by the NIGEB Institutional Animal Care and Use Committee. Studies were performed in accordance with the guidelines for the Care and Use of Laboratory Animals (IR.NIGEB.EC.1394.8.10.A).

\subsection{In vivo and in vitro Blastocyst Production}

Female NMRI mice (6-8 weeks old) were induced to superovulate by intraperitoneal injection of 7 IU equine chorionic gonadotropin (eCG; Folligon, Intervet, Spain) followed by 7 IU human chorionic gonadotropin 48 hours later (hCG; Pregnyl, Daroupakhsh, Tehran, Iran). For in vivo blastocyst collection, 21 superovulated female mice (seven in each replicate) were placed overnight with fertile males from the same strain (1:1).
The success of mating was confirmed the next morning by checking the vaginal plug. The date of plug detection considered E0.5. Mated females were sacrificed by cervical dislocation and blastocysts were obtained at E4.5 by flushing each uterine horn with HEPES buffered M2 medium (M7167; Sigma-Aldrich, St. Louis, MO, USA) and then cultured in KSOM (MR-121-L; Millipore, Billerica, MA, USA) medium at $37^{\circ} \mathrm{C}$ in a highly humidified atmosphere containing 5\% CO2 under a mineral oil overlay (M5310; Sigma-Aldrich).

For in vitro blastocyst production, 12-14 hours after hCG injection, 42 superovulated female mice (13-15 for each replicate) were sacrificed by cervical dislocation. Cumulus-oocyte complexes (COCs) were obtained from the ampulla of the oviducts and washed into the M2 medium. After washing, groups of 10-15 COCs were placed in $50 \mu \mathrm{L}$ droplet of human tubal fluid (HTF) medium (36)supplemented with 6 mg.mL-1 BSA (A6003; Sigma-Aldrich), 36.3 mg.mL-1 sodium pyruvate (P5280; Sigma-Aldrich) and $30.7 \mathrm{mg} . \mathrm{mL}-$ 1glutathione (G4251; Sigma-Aldrich). The sperm was obtained by mincing the vasa deferentia and each cauda epididymides male NMRI mice (8-10 weeks old) into HTF medium. The sperm dish was placed in the incubator under conditions described earlier for 30 minutes to allow the sperm swim out. Capacitated sperms were then added to HTF droplets containing oocytes for a final concentration of $1 \times 106 / \mathrm{mL}$. After four hours, presumptive zygotes were washed and cultured in KSOM medium to the blastocyst stage. Finally, morphologically normal expanded blastocysts with thinning zona were selected for the next experiments.

\subsection{RNA Isolation and Real-time RT-PCR}

Total RNA was isolated from 100 blastocysts for three replicates in each group (32-35 blastocysts in each replicate), using RNase plus Micro Kit (Qiagen, Valencia, CA, USA) in accordance with the manufacturer's protocol. The extracted RNA was converted into cDNA by AccuPower RocketScript ${ }^{\text {" }}$ RT PreMix kit (Bioneer, Daejeon, Korea) using random hexamer primers. The PCR reaction was prepared at the final volume of $15 \mu \mathrm{L}$ by mixing $7.5 \mu \mathrm{L}$ of $2 \mathrm{X}$ SYBR Green PCR Master Mix (25344; Intron, Seongnam-Si, Gyeonggi-do, Korea), $3 \mu \mathrm{L}$ of cDNA, and $0.2 \mu \mathrm{M}$ of each primer. Subsequently, real-time PCR was performed with a ABI System (Applied BiosystemsStepOne, Foster City, CA, USA) under the following thermal conditions: $95^{\circ} \mathrm{C}$ for two minutes, 40 cycles of $95^{\circ} \mathrm{C}$ for 10 seconds, and $58^{\circ} \mathrm{C}$ for 30 seconds. After 40 cycles, melting curves were analyzed to confirm the specificity of PCR products. Finally, relative expression of each gene was determined by the $2^{-\Delta \Delta \mathrm{Ct}}$ method, using $B 2 m$ (beta-2microglobulin) as the reference gene $(37,38)$. The sequences of the used primers (synthesized by TaqCopenhagen, Copenhagen, Denmark) are listed in Table 1. 
Table 1: Primer sequences for RT-PCR analysis

\begin{tabular}{|c|c|c|c|}
\hline Gene & Accession Number & Primer Sequence ( 5 to $3^{\prime}$ ) & Product Size \\
\hline $\operatorname{Trp53}$ & NM_011640 & $\begin{array}{l}\text { F: TGGAGGAGTCACAGTCGGAT } \\
\text { R: CGTCCATGCAGTGAGGTGAT }\end{array}$ & 117 \\
\hline Bax & NM_007527 & $\begin{array}{c}\text { F: GGTGCTCAAGGCCCTGTG } \\
\text { R: GGTCCCGAAGTAGGAGAGGAG }\end{array}$ & 142 \\
\hline Bcl2 & NM_009741 & $\begin{array}{l}\text { F: CTTCGCAGAGATGTCCAGTCAG } \\
\text { R: CCACAATCCTCCCCCAGTTCAC }\end{array}$ & 113 \\
\hline Pousf1 & NM_013633 & $\begin{array}{l}\text { F: AGCATTGAGAACCGTGTGAGG } \\
\text { R: TCGAACCACATCCTTCTCTAGC }\end{array}$ & 120 \\
\hline Nanog & NM_028016 & $\begin{array}{l}\text { F: GCCTCCAGCAGATGCAAGAA } \\
\text { R: GGTGCTGAGCCCTTCTGAAT }\end{array}$ & 154 \\
\hline$C d \times 2$ & NM_007673 & $\begin{array}{l}\text { F: GGAGGAAAAGTGAGCTGGCTG } \\
\text { R: CTCTCСTTGGCTCTGCGGTT }\end{array}$ & 85 \\
\hline Eomes & NM_010136 & $\begin{array}{l}\text { F: CCCACTGGATGAGGCAGGAGA } \\
\text { R: CCACACCGTCСTCTGTCACTT }\end{array}$ & 153 \\
\hline Gata6 & NM_010258 & $\begin{array}{l}\text { F: CAGGGGTAGGGGCATCAGTG } \\
\text { R: GCAGGGGAGGACAGACTGAC }\end{array}$ & 118 \\
\hline Grb2 & NM_008163 & $\begin{array}{l}\text { F: CACGGGTGGCATTGTGTGTC } \\
\text { R: AAGCAGGGGGGAAGGGAATC }\end{array}$ & 101 \\
\hline Mmp-9 & NM_013599 & $\begin{array}{c}\text { F: GCAAAGGCGTCGTGATCC } \\
\text { R: TGCCGTCCTTATCGTAGTCAG }\end{array}$ & 162 \\
\hline$B 2 m$ & NM_009735 & $\begin{array}{l}\text { F: CCTGGTCTTTCTGGTGCTTGT } \\
\text { R: GCAGTTCAGTATGTTCGGCTTC }\end{array}$ & 118 \\
\hline
\end{tabular}

F: forward; R: reverse.

\subsection{Experimental Design}

In order to investigate the effects of in vitro condition on embryo quality, after evaluation of blastocyst formation rate, the number of hatched blastocysts in IVF treatment and in vivo control groups were counted and compared; the hatching rate was measured as follow: number of hatching, hatched blastocysts/ total blastocyst. After that, the blastocysts were separately stored at $-80^{\circ} \mathrm{C}$ until RNA extraction. Finally, the transcript levels of the desired genes were quantified in both groups by realtime PCR.

\subsection{Statistical Analysis}

All experiments were repeated at least three times and results were expressed as mean \pm SD. The Student t-test was employed to analyze the experimental data. The SPSS version 16.0 was used for this analysis and P-value of $<0.05$ was considered statistically significant.

\section{Results}

4.1. Effect of In vitro Fertilization and Culture on Blastocyst Formation

To assess the impact of in vitro fertilization and culture media on developmental competence of embryo during preimplantation stages, the oocytes were fertilized and cultured in vitro for 96 hours. As shown in Table 2, a total of 351 two-cell embryos, 277 morulae, and 264 blastocysts (64.2\%, $50.55 \%$, and $48.17 \%$, respectively) were produced from in vitro fertilization of 548 oocytes.

Table 2. Development of in vitro fertilized mouse oocytes

\begin{tabular}{lcccc}
\hline Group & Oocytes, $\mathbf{N}$ & 2-Cell Embryo, N (\%) & Morula, N (\%) & Blastocyst, $\mathbf{N}(\%)$ \\
\hline In vitro fertilization & 548 & $351(64.2 \pm 2.79)$ & $277(50.55 \pm 2.56)$ & $264(48.17 \pm 1.77)$ \\
\hline
\end{tabular}

\subsection{Effect of In vitro Fertilization and Embryo} Culture on Hatching Rate of Embryos

To further investigate the effects of in vitro condition, morphologically normal expanded blastocysts of IVF treatment and in vivo control groups were cultured for further 12 hours and analyzed in terms of hatching rate. As shown in Figure 1, the percentage of hatched IVFproduced embryos $(62.8 \%)$ was significantly $(\mathrm{P}<0.05)$ lower than that of their in vivo $(68.47 \%)$ counterparts.

4.3. Effect of IVF and Embryo Culture on Developmentally Important Genes

The relative expression of all genes is presented in Figure 2. The results revealed that the expression levels of pluripotency genes were significantly $(P<0.05)$ higher in IVF-produced blastocysts than the fresh ones (4.49- and 1.47-fold, for Nanog and Pou5f1 respectively). However the expression of $C d x 2$, Gata6, Grb2, and Mmp9 showed a significant decrease (-5.58-, $-2.71-,-5.46-$, and -10.77-fold, respectively) in the in vitro group. Although the expressions of $\mathrm{Bax}$ and $\mathrm{Bcl} 2$ were comparatively lower (-2.48-, and -3.32-fold, respectively) in the in vitro embryos, the differences in the $B a x: B c l 2$ ratio (1.34-fold; $\mathrm{P}=0.213$ ) was not statistically significant. The expression of Eomes (1.26fold, $\mathrm{P}=0.088$ ) and Trp53 (1.03-fold; $\mathrm{P}=0.306$ ) was similar in both experimental groups. 


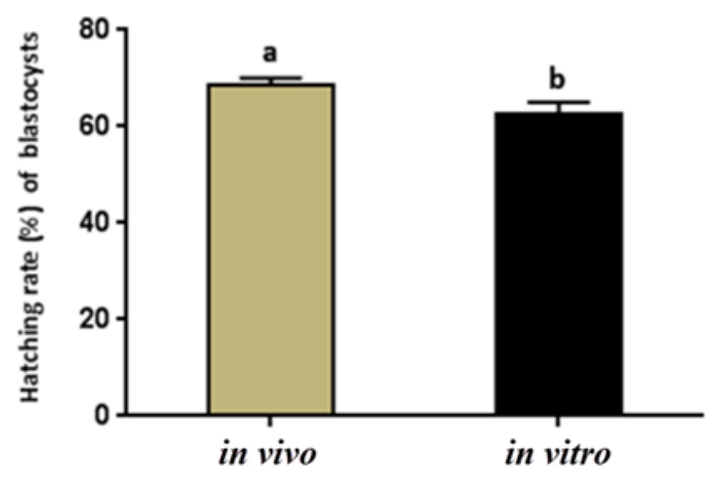

Figure 1. Hatching rates (\%) of in vivo and in vitro produced blastocysts. ${ }^{\text {a,b }}$, different letters in the bars indicate statistically significant differences between the experimental groups $(\mathrm{P}<0.05)$.

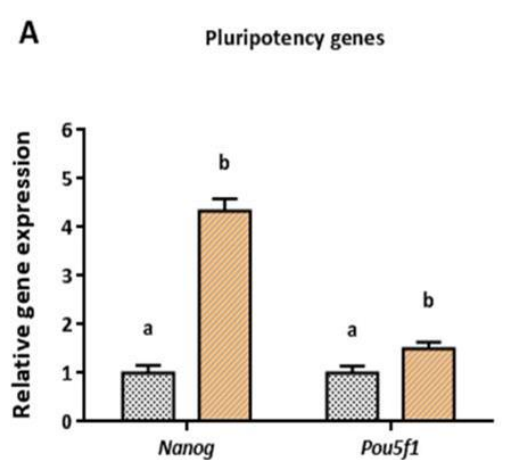

D

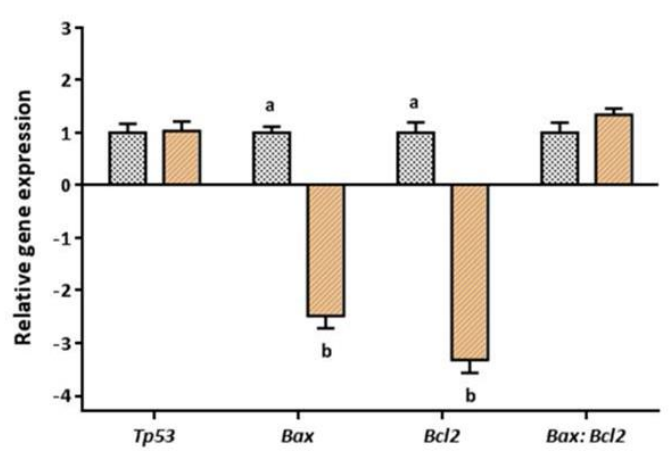

B

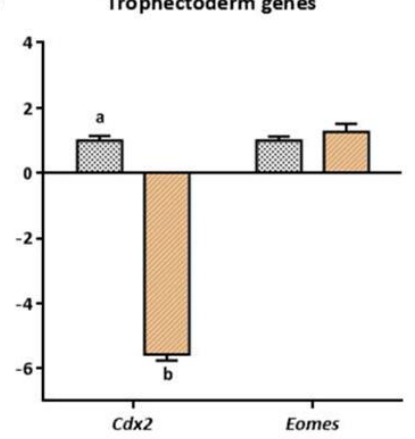

E Implantation gene

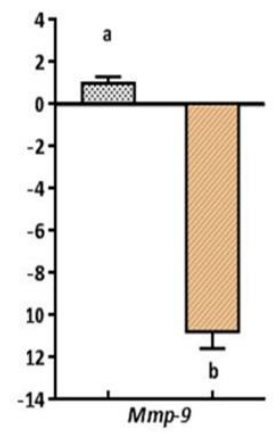

C

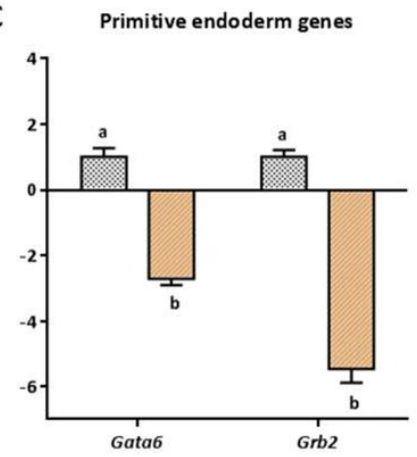

Figure 2. Relative expression of selected genes related to (A) pluripotency, (B) the trophectoderm lineage, (C) the primitive endoderm, (D) apoptosis, and $(\mathrm{E})$ implantation. Statistically significant differences are indicated by ${ }^{\mathrm{a}, \mathrm{b}}(\mathrm{P}<0.05)$.

\section{Discussion}

The current study aimed at assessing the impacts of IVF and IVC on the quality of embryos. According to obtained results, hatching rate was significantly lower in the IVF-derived embryos than in the in vivo control. Although a correct hatching process occurs normally in a good quality blastocyst, it is shown that in vitro conditions cause zona hardening, and disturb the hatching ability of a produced embryo(39). Furthermore, the success of in vitro hatching is dependent on a sufficiently high number of embryonic cells(40) as well as trophectodermal lysins (41). Schiewe et al., reported that culture conditions may reduce the production of intrinsic embryonic lysin that promotes hatching (42).

To further elucidate how in vitro condition might affect the embryo quality, relative expression levels of Mmp-9, which is also referred to as gelatinase $\mathrm{B}$, was examined (43). The results of the current study (Fig. 2) indicated a significantly lower expression level of Mmp-9 in in vitro-produced mouse blastocysts compared with the in vivo-produced ones. The expression of $M m p-9$ by trophoblast cells, which possesses basement membranedegrading proteolytic activity, is required for successful implantation and trophoblast invasion $(43,44)$. It seems 
that in vitro culture condition, through a reduction of hatching rate and $\mathrm{Mmp}-9$ expression, can be related to low implantation rate reported in previous studies (45, 46).

Shortly before implantation, the late blastocyst contains three distinct cell types: epiblast, which forms the future embryo, trophectoderm, which gives rise to the prospective placenta, and primitive endoderm, which forms the yolk sac $(30,47)$. In the current study, IVF and IVC significantly increased the expression levels of Pou5f1 and Nanog in the mouse blastocyst. The obtained results were in agreement with those of Henderson et al. (48), observing enhanced expression of Pousf1 and Nanog in the in vitro-produced rabbit blastocyst. Purpera et al., also reported a significant upregulation of Pousf1 mRNA in in vitro bovine blastocysts compared with their in vivo counterparts (49). Pou5f1 and Nanog are the most critical transcription factors forcreating and maintaining the pluripotency of inner cell mass, epiblast, and embryonic stem cells, as well as the first two lineage differentiation in blastocyst (50). According to the role of these key factors, changing their expression levels can presumably interfere with normal differentiation and developmental competence of embryo (15). In the current study, the expression of $C d x 2$ was significantly lower in IVFproduced embryos, while no difference was found about Eomes. In contrast, Giritharan et al., (24) reported a decrease (about -2-fold) in Eomes expression in in vitroproduced mouse blastocyst. $\mathrm{Cdx} 2$ and Eomes are two important factors required for trophectoderm differentiation and development (51). Furthermore, $\mathrm{Cd} \times 2$ and Pou5f1 have mutual inhibitory activity, where Cdx2 inhibits Pou5f1 in trophectodermcells, and Pou $5 \mathrm{f} 1$ inhibits expression of $C d x 2$ in the inner cell mass $(52,53)$. In the current study, reduction in expression of $C d x 2$ and an elevation in the expression of the Pousf1 show this antagonistic regulation, which in this case can direct cell differentiating toward the inner cell mass (54). Low expression of $C d x 2$ was in accordance with that of the study by Giritharan et al. (24), in which IVF reduced the trophectoderm cell numbers. Both of these reductions (in cell number and gene expression) can influence trophectoderm-specific downstream developmental events such as trophoblast development, implantation, mesoderm, and placenta formation, and therefore, would perturb normal embryo development $(51,55)$. The current study results revealed that IVF and IVC cause a reduction in the expression of Gata6 and Grb2. Grb2 and Gata6 are two essential transcription factors to differentiate and form primitive endoderm in blastocyst (56). According to the fact that the differentiation of primitive endoderm and epiblast occurs due to antagonistic effect of Gata6 and Nanog factors, a reduction in Gata6 and increase in Nanog expression may reinforce leading to the epiblast population, which therefore can perturb the yolk sac formation and post-implantation embryo development $(30,54)$.

Programmed cell death or apoptosis, initiating cell death under suboptimal conditions, plays a vital role in the development of the embryo (57). The current study results showed that although the expression levels of $B a x$ and $B c l 2$ decreased in the in vitro group, no significant differences were observed in either the expression of Trp53 or in the Bax:Bcl 2 ratio between in vitro blastocysts and their in vivo counterparts. The $\operatorname{Trp} 53$ is a transcription factor that in response to stress signals activates many downstream target genes including $B a x$, which can overcome the anti-apoptotic effects of $B c l 2$ and accelerated cell death (35). Thus, the fate of a cell in response to stress can be influenced by Trp53, which regulates the ratio of $\mathrm{Bax}: \mathrm{Bcl} 2$ protein level (58). Since the ratio of $B a x: B c l 2$ is a reliable parameter to predict the tendency of embryo towards survival or apoptosis (34), the current study results indicated a normal in vitro condition in terms of apoptosis.

\section{Conclusions}

The collected data gave further evidence supporting the effects of in vitro culture on expression levels of developmental and apoptosis important genes. The expressions of pluripotency genes were significantly higher in IVF-produced blastocysts; whereas, $C d x 2$, Gata6, and Grb2 showed a significant decrease in the in vitro group compared with the fresh ones. In addition, the current study provided a possible explanation for the lower implantation rate of in vitro-produced blastocysts compared with those of the in vivo origin, regarding a sharp decrease in Mmp-9 expression level. However, further investigations are required to clarify whether returning to normal expression levels of $\mathrm{Mmp}-9$ through providing an appropriate environment would improve the implantation rate.

\section{Acknowledgments}

Authors wish to thank the National Institute of Genetic Engineering and Biotechnology (NIGEB) for providing the facilities to conduct the study.

\section{Financial Support}

This work was financially supported by the Iran National Science Foundation (INSF); grant number: 93022945.

\section{Conflict of interest}

The authors declared no conflict of interest.

\section{References}

1. Calle A, Fernandez-Gonzalez R, Ramos-Ibeas P, Laguna-Barraza R, Perez-Cerezales S, Bermejo-Alvarez $\mathrm{P}$, et al. Long-term and transgenerational effects of in vitro culture on mouse embryos. Theriogenology. 
2012;77(4):785-793.

doi: 10.1016/j.theriogenology.2011.07.016

pmid: 21855990

2. Calle A, Miranda A, Fernandez-Gonzalez R, Pericuesta E, Laguna R, Gutierrez-Adan A. Male mice produced by in vitro culture have reduced fertility and transmit organomegaly and glucose intolerance to their male offspring. Biol Reprod. 2012;87(2):34. doi: 10.1095/biolreprod.112.100743 pmid: 22649070

3. Gasperowicz M, Natale DR. Establishing three blastocyst lineages--then what? Biol Reprod. 2011;84(4):621-630. doi: 10.1095/biolreprod.110.085209 pmid: 21123814

4. Lonergan P, Rizos D, Kanka J, Nemcova L, Mbaye AM, Kingston $\mathrm{M}$, et al. Temporal sensitivity of bovine embryos to culture environment after fertilization and the implications for blastocyst quality. Reproduction. 2003;126(3):337-346. pmid: 12968941

5. Johnston LA, Donoghue AM, O'Brien SJ, Wildt DE. Influence of temperature and gas atmosphere on invitro fertilization and embryo development in domestic cats. J Reprod Fertil. 1991;92(2):377-382. pmid: 1909365

6. Rinaudo PF, Giritharan G, Talbi S, Dobson AT, Schultz RM. Effects of oxygen tension on gene expression in preimplantation mouse embryos. Fertil Steril. 2006;86(4 Suppl):1252-1265, 1265 e1251-1236. doi: 10.1016/j.fertnstert.2006.05.017 pmid: 17008149

7. Camargo LSdA, Viana JHM, Sá WFd, Ferreira AdM, Ramos AdA, Vale Filho V. Factors influencing in vitro embryo production. Anim Reprod. 2006;3(1):19-28.

8. Summers MC, McGinnis LK, Lawitts JA, Biggers JD. Mouse embryo development following IVF in media containing either L-glutamine or glycyl-L-glutamine. Hum Reprod. 2005;20(5):1364-1371. doi: 10.1093/humrep/deh756 pmid: 15705624

9. Quea G, Romero K, Garcia-Velasco JA. Extended embryo culture to increase implantation rate. Reprod Biomed Online. 2007;14(3):375-383. doi: 10.1016/s1472-6483(10)60882-6 pmid: 17359595

10. Aviles M, Gutierrez-Adan A, Coy P. Oviductal secretions: will they be key factors for the future ARTs? Mol Hum Reprod. 2010;16(12):896-906. doi: 10.1093/molehr/gaq056 pmid: 20584881

11. Doherty AS, Mann MR, Tremblay KD, Bartolomei MS, Schultz RM. Differential effects of culture on imprinted H19 expression in the preimplantation mouse embryo. Biol Reprod. 2000;62(6):1526-1535. doi: 10.1095/biolreprod62.6.1526 pmid: 10819752

12. de Oliveira AT, Lopes RF, Rodrigues JL. Gene expression and developmental competence of bovine embryos produced in vitro under varying embryo density conditions. Theriogenology. 2005;64(7):15591572. doi: 10.1016/j.theriogenology.2005.03.019 pmid: 15878193

13. Niemann H, Wrenzycki C. Alterations of expression of developmentally important genes in preimplantation bovine embryos by in vitro culture conditions: implications for subsequent development. Theriogenology. 2000;53(1):21-34. doi: 10.1016/S0093-691X(99)00237-X pmid: 10735059

14. Sananmuang T, Tharasanit T, Nguyen C, Phutikanit N, Techakumphu M. Culture medium and embryo density influence on developmental competence and gene expression of cat embryos. Theriogenology. 2011;75(9):1708-1719. doi: 10.1016/j.theriogenology.2011.01.008 pmid: 21396699

15. Rinaudo P, Schultz RM. Effects of embryo culture on global pattern of gene expression in preimplantation mouse embryos. Reproduction. 2004;128(3):301-311. doi: $10.1530 /$ rep.1.00297 pmid: 15333781

16. Gardner DK, Lane M. Ex vivo early embryo development and effects on gene expression and imprinting. Reprod Fertil Dev. 2005;17(3):361-370. doi: 10.1071/RD04103 pmid: 15745644

17. Lane M, Gardner DK. Amino acids and vitamins prevent culture-induced metabolic perturbations and associated loss of viability of mouse blastocysts. Hum Reprod. 1998;13(4):991-997. doi: 10.1093/humrep/13.4.991 pmid: 9619560

18. Koot YE, Macklon NS. Embryo implantation: biology, evaluation, and enhancement. Curr Opin Obstet Gynecol. 2013;25(4):274-279. doi: 10.1097/GCO.0b013e3283630d94 pmid: 23787799

19. Ng EHY, Yeung WSB, Lau EYL, So WWK, Ho PC. High serum oestradiol concentrations in fresh IVF cycles do not impair implantation and pregnancy rates in subsequent frozen-thawed embryo transfer cycles. Hum Reprod. 2000;15(2):250-255.

20. Pollard J, Leibo S. Chilling sensitivity of mammalian embryos. Theriogenology. 1994;41(1):101-106.

21. Duby R, Hill J, O'Callaghan D, Overstrom E, Boland M. Changes induced in the bovine zona pellucida by ovine and bovine oviducts. Theriogenology. 1997;47(1).

22. Slimane W, Heyman Y, Lavergne Y, Humblot P, Renard JP. Assessing chromosomal abnormalities in two-cell bovine in vitro-fertilized embryos by using fluorescent in situ hybridization with three different cloned probes. Biol Reprod. 2000;62(3):628-635. pmid: 10684804

23. Crosier AE, Farin PW, Dykstra MJ, Alexander JE, Farin CE. Ultrastructural morphometry of bovine blastocysts produced in vivo or in vitro. Biol Reprod. 2001;64(5):1375-1385.

10.1095/biolreprod64.5.1375 pmid: 11319141

24. Giritharan G, Talbi S, Donjacour A, Di Sebastiano F, Dobson AT, Rinaudo PF. Effect of in vitro fertilization on gene expression and development of mouse preimplantation embryos. Reproduction. 2007;134(1):63-72. doi: 10.1530/REP-06-0247 pmid: 17641089

25. Lonergan P, Fair T, Corcoran D, Evans AC. Effect of culture environment on gene expression and developmental characteristics in IVF-derived embryos. Theriogenology. 2006;65(1):137-152. doi: $10.1016 /$ j.theriogenology.2005.09.028 pmid: 16289260

26. Carrasco B, Boada M, Rodriguez I, Coroleu B, Barri PN, Veiga A. Does culture medium influence offspring birth weight? Fertil Steril. 2013;100(5):1283-1288. doi: 10.1016/j.fertnstert.2013.07.006 pmid: 23916797

27. Lane M. Mechanisms for managing cellular and homeostatic stress in vitro. Theriogenology. 2001;55(1):225-236. doi: 10.1016/S0093691X(00)00456-8 pmid: 11198084

28. Kovai B, Vlaisavljevi V. Importance of Blastocyst Morphology in Selection for Transfer. Advances in embryo transfer: IntechOpen; 2012. p. 161. 
29. Barahona P, Leigh D, Ritchie W, McArthur SJ, Jansen RP. Array CGH and Partial Genome Sequencing for Rapidly Karyotyping IVF Blastocysts Before Single Transfer. Screening the Single Euploid Embryo: Springer; 2015. p. 163-178.

30. Cockburn K, Rossant J. Making the blastocyst: lessons from the mouse. J Clin Invest. 2010;120(4):995-1003. doi: $10.1172 / J C I 41229$ pmid: 20364097

31. Arnold SJ, Robertson EJ. Making a commitment: cell lineage allocation and axis patterning in the early mouse embryo. Nat Rev Mol Cell Biol. 2009;10(2):91-103. doi: 10.1038/nrm2618 pmid: 19129791

32. Chazaud C, Yamanaka Y, Pawson T, Rossant J. Early lineage segregation between epiblast and primitive endoderm in mouse blastocysts through the Grb2MAPK pathway. Dev Cell. 2006;10(5):615-624. doi: 10.1016/j.devcel.2006.02.020 pmid: 16678776

33. Chen L, Nakai M, Belton RJ, Jr., Nowak RA. Expression of extracellular matrix metalloproteinase inducer and matrix metalloproteinases during mouse embryonic development. Reproduction. 2007;133(2):405-414. doi: 10.1530/rep.1.01020 pmid: 17307908

34. Dhali A, Anchamparuthy VM, Butler SP, Pearson RE, Mullarky IK, Gwazdauskas FC. Gene expression and development of mouse zygotes following droplet vitrification. Theriogenology. 2007;68(9):1292-1298. doi: $10.1016 /$ j.theriogenology.2007.08.030 pmid: 17915304

35. Elmore S. Apoptosis: a review of programmed cell death. Toxicol Pathol. 2007;35(4):495-516. doi: 10.1080/01926230701320337 pmid: 17562483

36. Quinn P, Warnes GM, Kerin JF, Kirby C. Culture factors affecting the success rate of in vitro fertilization and embryo transfer. Ann N Y Acad Sci. 1985;442(1):195-204. doi: 10.1111/j.17496632.1985.tb37520.x pmid: 3860035

37. Du T, Jia J, Lin X, Xie R, Li J, Xiao D, et al. Generation of Rm21LG transgenic mice: a powerful tool to generate conditional overexpression of miR-21 that is involved in oncogenesis. Biotechnol Lett. 2014;36(1):920. doi: $10.1007 /$ s10529-013-1327-y pmid: 24068500

38. Choi YJ, Gurunathan S, Kim D, Jang HS, Park WJ, Cho $\mathrm{SG}$, et al. Rapamycin ameliorates chitosan nanoparticleinduced developmental defects of preimplantation embryos in mice. Oncotarget. 2016;7(46):7465874677. doi: 10.18632/oncotarget.10813 pmid: 27463007

39. Velásquez A, Manríquez J, Castro F, Rodríguez-Alvarez L. Effect of zona pellucida removal on early development of in vitro produced bovine embryos. Arch Med Vet. 2013;45(1).

40. Montag M, Koll B, Holmes P, van der V. Significance of the number of embryonic cells and the state of the zona pellucida for hatching of mouse blastocysts in vitro versus in vivo. Biol Reprod. 2000;62(6):1738-1744. doi: 10.1095/biolreprod62.6.1738 pmid: 10819778

41. Hammadeh ME, Fischer-Hammadeh C, Ali KR. Assisted hatching in assisted reproduction: a state of the art. J Assist Reprod Genet. 2011;28(2):119-128. doi: 10.1007/s10815-010-9495-3 pmid: 21042844

42. Schiewe MC, Hazeleger NL, Sclimenti C, Balmaceda JP. Physiological characterization of blastocyst hatching mechanisms by use of a mouse antihatching model ${ }^{*}{ }^{*}$ Presented in part at the 42 nd Annual Meeting of The Pacific Coast Fertility Society, Palm Springs, California, April 21 to 24, 1994. +Supported in part by a Department of Obstetrics and Gynecology Memorial Health Services grant at the University of California Irvine and by resources made available at the University of California Irvine-Beckman Laser Institute. Fertil Steril. 1995;63(2):288-294. doi: https://doi.org/10.1016/S0015-0282(16)57357-9

43. Staun-Ram E, Goldman S, Gabarin D, Shalev E. Expression and importance of matrix metalloproteinase 2 and 9 (MMP-2 and -9) in human trophoblast invasion. Reprod Biol Endocrinol. 2004;2(1):59. doi: 10.1186/1477-7827-2-59 pmid: 15294019

44. Peters TJ, Albieri A, Bevilacqua E, Chapman BM, Crane LH, Hamlin GP, et al. Differentiation-dependent expression of gelatinase B/matrix metalloproteinase-9 in trophoblast cells. Cell Tissue Res. 1999;295(2):287296. doi: $10.1007 / \mathrm{s} 004410051235$ pmid: 9931375

45. Koot YE, Teklenburg G, Salker MS, Brosens JJ, Macklon NS. Molecular aspects of implantation failure. Biochim Biophys Acta. 2012;1822(12):1943-1950. doi: 10.1016/j.bbadis.2012.05.017 pmid: 22683339

46. Ventura-Junca P, Irarrazaval I, Rolle AJ, Gutierrez JI, Moreno RD, Santos MJ. In vitro fertilization (IVF) in mammals: epigenetic and developmental alterations. Scientific and bioethical implications for IVF in humans. Biol Res. 2015;48(1):68. doi: 10.1186/s40659-015-0059-y pmid: 26683055

47. Kazemi P, Dashtizad M, Shamsara M, Mahdavinezhad F, Hashemi E, Fayazi S, et al. Effect of blastocoel fluid reduction before vitrification on gene expression in mouse blastocysts. Mol Reprod Dev. 2016;83(8):735742. doi: $10.1002 / \mathrm{mrd} .22681$ pmid: 27409768

48. Henderson GR, Brahmasani SR, Yelisetti UM, Konijeti S, Katari VC, Sisinthy S. Candidate gene expression patterns in rabbit preimplantation embryos developed in vivo and in vitro. J Assist Reprod Genet. 2014;31(7):899-911. doi: 10.1007/s10815-014-02330 pmid: 24760721

49. Purpera MN, Giraldo AM, Ballard CB, Hylan D, Godke RA, Bondioli KR. Effects of culture medium and protein supplementation on mRNA expression of in vitro produced bovine embryos. Mol Reprod Dev. 2009;76(8):783-793. doi: 10.1002/mrd.21028 pmid: 19288542

50. $\mathrm{Ng} \mathrm{HH}$, Surani MA. The transcriptional and signalling networks of pluripotency. Nat Cell Biol. 2011;13(5):490-496. doi: 10.1038/ncb0511-490 pmid: 21540844

51. Strumpf D, Mao CA, Yamanaka Y, Ralston A, Chawengsaksophak $\mathrm{K}$, Beck $\mathrm{F}$, et al. $\mathrm{Cd} \mathrm{d} 2$ is required for correct cell fate specification and differentiation of trophectoderm in the mouse blastocyst. Development. 2005;132(9):2093-2102. doi: 10.1242/dev.01801 pmid: 15788452

52. Lanner F. Lineage specification in the early mouse embryo. Exp Cell Res. 2014;321(1):32-39. doi: 10.1016/j.yexcr.2013.12.004 pmid: 24333597

53. Niwa H, Toyooka Y, Shimosato D, Strumpf D, Takahashi K, Yagi R, et al. Interaction between Oct3/4 and $\mathrm{Cd} \times 2$ determines trophectoderm differentiation. Cell. 2005;123(5):917-929. doi: 10.1016/j.cell.2005.08.040 pmid: 16325584 
54. Oron E, Ivanova N. Cell fate regulation in early mammalian development. Phys Biol. 2012;9(4):045002. doi: 10.1088/14783975/9/4/045002 pmid: 22871593

55. Awonuga AO, Zhong W, Abdallah ME, Slater JA, Zhou SC, Xie YF, et al. Eomesodermin, HAND1, and CSH1 proteins are induced by cellular stress in a stressactivated protein kinase-dependent manner. Mol Reprod Dev. 2011;78(7):519-528. doi: 10.1002/mrd.21342 pmid: 21710638
56. Wang Y, Smedberg JL, Cai KQ, Capo-Chichi DC, Xu XX. Ectopic expression of GATA6 bypasses requirement for $\mathrm{Grb} 2$ in primitive endoderm formation. Dev Dyn. 2011;240(3):566-576. doi: 10.1002/dvdy.22447 pmid: 20925113

57. Jacobson MD, Weil M, Raff MC. Programmed cell death in animal development. Cell. 1997;88(3):347354. pmid: 9039261

58. Hemann MT, Lowe SW. The p53-Bcl-2 connection. Cell Death Differ. 2006;13(8):1256-1259. doi: $10.1038 /$ sj.cdd.4401962 pmid: 16710363 